\title{
O baú do Laurimar: documentos biográficos e narrativas da cultura em Santarém/PA
}

\section{Laurimar's chest: biographic documents and cultural narratives in Santarém/PA}

\author{
Luciana Gonçalves de Carvalho* \\ Osinaldo Raphael Lima dos Santos Filho ${ }^{* *}$ \\ Elber Norton Souza dos Santos***
}

Palavras-chave:

História de vida (Laurimar

Leal)

Arquivos pessoais

Cultura

\begin{abstract}
Resumo: Relatos biográficos de Laurimar dos Santos Leal, contados com o auxílio de documentos íntimos arquivados em um velho baú de madeira abrigado no chamado "museu da cidade", são o fio condutor deste artigo que investiga a relação desse indivíduo com o campo institucional da cultura em Santarém, no Pará. Laurimar é artista plástico, compositor, carnavalesco, restaurador e colecionador, e, foi, por muitos anos, diretor do Centro Cultural João Fona - principal instituição museológica de Santarém. Em inúmeras sessões de entrevistas que resultam no registro de sua história de vida, constatam-se interseções frequentes entre os domínios público e privado em sua trajetória, revelando que ela própria está intimamente atrelada à institucionalização de espaços e práticas estruturantes do campo da cultura no município.
\end{abstract}

\begin{abstract}
Biographical accounts about Laurimar dos Santos Leal, reconstructed with the aid of personal documents stored in an old wooden chest at the "town museum" in Santarém, Pará, Brazil, are the guiding thread of this article, which investigates his relations with the institutional field of culture in Santarém. Santos Leal is a visual artist, composer, carnival producer, restorer and collector who worked for many years as director of the João Fona Cultural Center - the main museum in Santarém. In numerous interview sessions that provide a record of his life story, frequent intersections were identified between the public and private realms in his life path, showing that it is intimately linked to the institutionalization of spaces and practices that play a structural role in the local cultural field.
\end{abstract}

Recebido em 26 de junho de 2019. Aprovado em 19 de agosto de 2019.

\section{Introdução}

Santarém é uma cidade média que abriga cerca de 300 mil habitantes na porção ocidental do Pará, no norte do Brasil. O cenário privilegiado de sua ocupação é a foz do rio Tapajós, afluente que, pela margem direita, despeja no Amazonas barrento suas águas claras. Em uma longa faixa multicor, os dois grandes rios correm lado a lado, sem se misturarem, formando o chamado encontro das águas. Esse fenômeno, explicado por propriedades hídricas naturais, assume tamanho valor simbólico e afetivo para a população local que foi reconhecido como "patrimônio cultural do Pará" pela Lei Estadual no 8.062/2014.

$\mathrm{O}$ encontro das águas pode ser apreciado de vários pontos na área central da cidade, mas é na praça São Sebastião, localizada à beira-rio entre os bairros do Centro e da Prainha, ${ }^{1}$ que se pode experimentar um dos costumes mais típicos dos fins de tarde santarenos. Tendo, ao fundo, essa paisagem que foi eleita em 2014 como "a cara de Santarém",

\footnotetext{
* Doutora em Ciências Humanas - Antropologia (PPGSA/UFRJ) - 2005; mestra em Sociologia (PPGSA/UFRJ) - 1997; bacharel em Ciências Sociais (UFRJ) - 1994. Professora na Universidade Federal do Oeste do Pará desde 2010, atuando nos cursos de graduação em Antropologia, no mestrado em Ciências da Sociedade e no doutorado em Sociedade, Natureza e Desenvolvimento (Ciências Ambientais). Coordena o Programa de Extensão Patrimônio Cultural na Amazônia (Proext/MEC), com atuação na região da Calha Norte desde 2010. E-mail: <lu_gcarvalho@yahoo.com.br>.

** Bacharel em Antropologia. E-mail: <osinaldofilho@hotmail.com>.

*** Bacharel em Antropologia. E-mail: <elber.norton@gmail.com>.
} 
com mais de 70\% dos votos em uma enquete realizada por um portal eletrônico de notícias (PORTAL G1, 2014), alguns moradores proseiam na frente de casa, enquanto outros se exercitam no calçadão da orla, crianças brincam, jovens namoram, e barulhentos passarinhos vão-se acomodando nas copas das árvores. Na face da praça que se volta para o rio, está o único imóvel tombado no município (por decreto municipal de 2011): o Centro Cultural João Fona (CCJF), que é carinhosamente designado como "museu da cidade", em alusão às suas coleções de artefatos arqueológicos, documentos e outros objetos portadores de memórias locais.

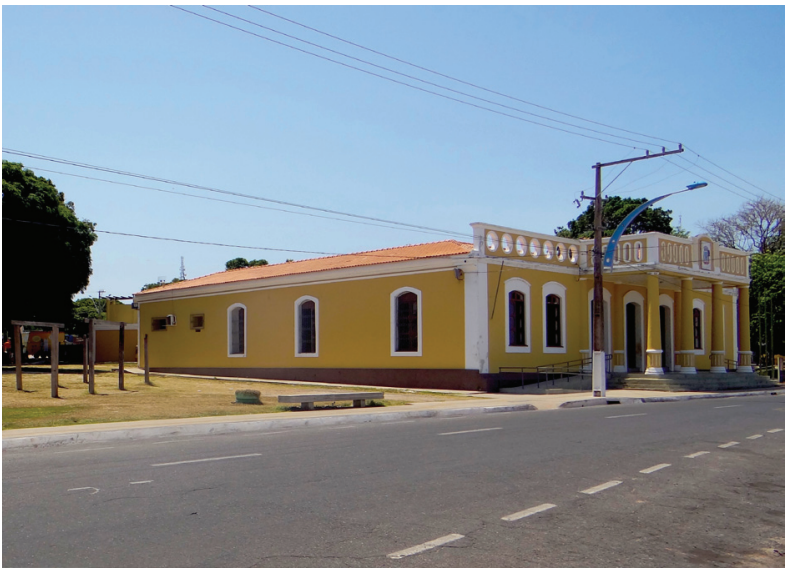

Figura 1: Centro Cultural João Fona

Fonte: Igor Erick (2017) Acervo Pepca/Ufopa.

Característico da arquitetura colonial brasileira, o prédio foi construído entre 1853 e 1867, constituindo um marco importante do processo de expansão urbana de Santarém (SANTOS, 1999). Originalmente destinado a abrigar a Câmara Municipal e a Cadeia Pública, também foi utilizado como Intendência Municipal, Tribunal do Júri e Prefeitura, cumprindo várias funções públicas. Sua transformação em centro cultural foi determinada pela Lei Municipal no 13.791/91, segundo a qual: “[...] o Centro Cultural João Fona será utilizado exclusivamente com finalidades culturais, dando-se prioridade para a instalação, em suas dependências, de um museu capaz de fornecer uma visão abrangente da História”. O prédio foi, então, restaurado; e, em 1994, para lá foram transferidas coleções particulares de algumas das mais renomadas famílias de Santarém.

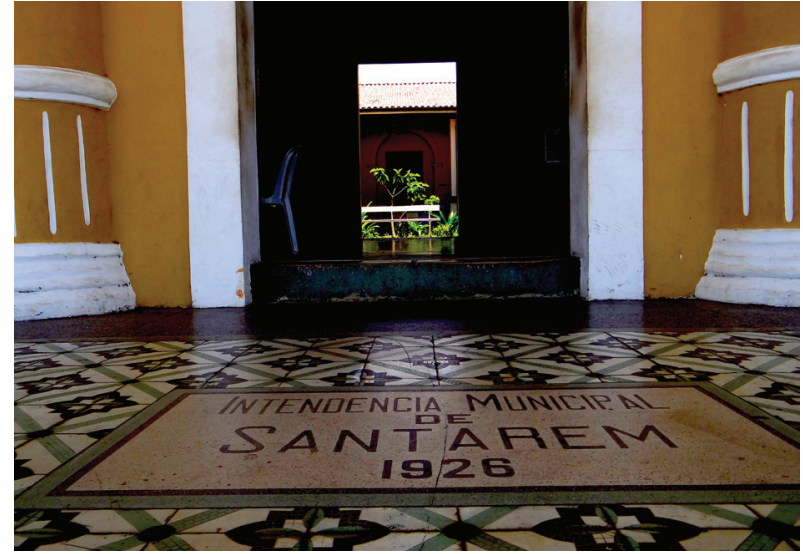

Figura 2: Entrada do Centro Cultural João Fona. Ao fundo, o banco em que Laurimar recebia os visitantes. Fonte: Igor Erick (2017). Acervo Pepca/Ufopa.

No pátio interno do imóvel, sentado em um banco emoldurado por arbustos, um homem cego acompanha os ritos do crepúsculo vespertino com a audição bem apurada. Trata-se de Laurimar dos Santos Leal, artista plástico, compositor, carnavalesco, restaurador, colecionador, curador de exposições e diretor do centro, que, até as horas finais do expediente, recebe turistas, visitantes e amigos como se estivesse em casa. Laurimar contalhes a história do prédio, relembra como um ou outro objeto chegou ali, conversa sobre a vida e orienta, por exemplo: "Comece a andar por aqui, veja aqueles quadros, olha as cerâmicas, ali a sala dos pretos escravos, vá e volte aqui comigo". Não se deixa o lugar sem tornar a passar pelo anfitrião; e não se volta a ele sem perguntar: "Cadê Laurimar"?

Foi assim que Laurimar Leal capturou a atenção da equipe responsável por este trabalho, cujo objetivo original era reconstituir, com o auxílio de documentos previamente identificados e entrevistas, o histórico de formação do acervo do "museu da cidade". ${ }^{2}$ No decorrer das visitas ao CCJF, ele crescia como protagonista da narrativa em construção, agindo e falando como parte integrante do próprio centro cultural. "Aqui eu moro; lá eu passo um tempo" - disse uma vez, referindose respectivamente ao centro e à sua residência, enfatizando ser o primeiro o "espaço que [lhe] concede intimidade e hospitalidade" (DA MATTA, 1991, p. 60). Afinal, era ali que recebia os amigos e, como se fosse o dono da casa, dispensava-lhes carinho e consideração. 
A relação do indivíduo com a instituição tanto chamou atenção que o trabalho passou a se concentrar no registro de relatos biográficos do septuagenário diretor do CCJF, não só por causa de sua notoriedade ou da eloquência de seus comentários sobre artes e a cultura local, mas, sobretudo, por causa da forte imbricação entre as esferas pública e privada que suas narrativas denotavam. Certamente, essa imbricação tivera implicações nas coleções formadas e abrigadas pelo centro - as quais, durante o trabalho realizado, não se sabia mais a quem pertenciam, se à instituição ou ao seu diretor -, bem como nas demais atividades institucionais (exposições, eventos literários, performances artísticas e outras manifestações). Contudo, iriam além das paredes do prédio, como revelaria o velho baú de madeira mencionado no título deste artigo.

Era maio de 2011 quando Laurimar Leal pediu ajuda para organizar o conteúdo desse baú, que mantinha trancado à chave em um canto sombrio e empoeirado do imóvel, para onde ele mesmo o trouxera. Referido como "o baú do Laurimar", o móvel se confundia com o acervo da casa, e, como grande parte desse acervo, estava deteriorado pelo tempo e pelo acondicionamento impróprio. Todo o seu conteúdo estava ameaçado por pragas, mofo e poeira acumulada, além de alagamentos provocados pelas fortes chuvas do inverno amazônico. Em seu interior, documentos íntimos misturavam-se a correspondências institucionais, fragmentos de louça e cerâmica arqueológica, além de manuscritos do século XIX e do início do século $\mathrm{XX}$, que continham registros da vida pública de Santarém e outros municípios da região do Baixo Amazonas. Indistintamente armazenados no baú a mais significativa expressão material da interseção das esferas pública e privada na vida de Laurimar Leal - esses documentos perfaziam, no conjunto, a "escrita de si" que ele elaborou à frente do CCJF (FOUCAULT, 1986).

Como demonstrou Garcia (1998, p. 175), "[...] o caráter exclusivamente privado de um arquivo [pessoal] foi e é uma questão problemática", não só porque arquivos originariamente privados podem ser transferidos a entes públicos, como frequentemente acontece, mas também porque, historicamente, são fluidas as fronteiras entre o público e o privado nas trajetórias de indivíduos que acumulam funções públicas. Situado, pois, na interseção entre arquivos pessoais e institucionais, e tomado como suporte de memórias individuais e coletivas, o baú de Laurimar motivou múltiplos relatos biográficos e narrativas culturais que puderam ser reconstituídas a partir dos fragmentos nele guardados, então reagrupados em uma escrita inteligível de uma vida pública-privada. Revelou, por assim dizer, uma trajetória de vida entrelaçada à própria formação do campo institucional da cultura em Santarém, entendida como o processo pelo qual um conjunto de medidas adotadas por artistas, intelectuais e autoridades locais, de forma mais ou menos sistemática, conduziu à ocupação de espaços públicos e privados por determinadas práticas e expressões culturais, bem como à criação de instituições específicas voltadas para a promoção e a gestão daqueles espaços, práticas e expressões (CALABRE, 2007; URFALINO, 2004).

Como se quer demonstrar, tal processo engendrou inovações forjadas no âmbito de um projeto de modernização de Santarém à luz de um modelo de civilização ${ }^{3}$ concebido nos trânsitos e nas experiências de determinados sujeitos em circuitos culturais externos. Movimentando-se entre eles e a terra natal, indivíduos como Laurimar Leal puderam adquirir conhecimentos eruditos sobre arte $\mathrm{e}$ cultura e formar novos padrões estéticos de forma e conteúdo (DI MAGGIO, 2015; GANS, 1999), vindo a influenciar a emergência - ou a invenção, nos termos de Urfalino (2004) - de políticas públicas de cultura para Santarém, na últimas décadas do século XX.

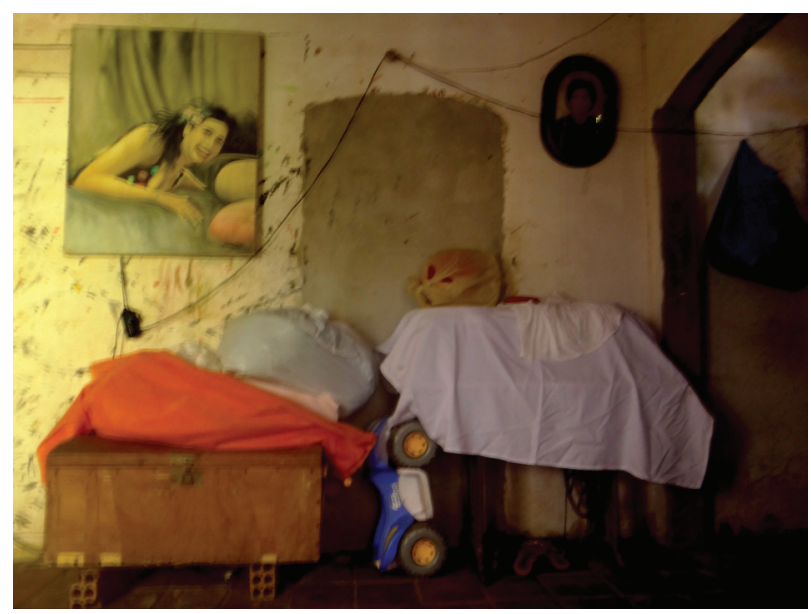

Figura 3: Baú entre obras de Laurimar Leal Fonte: Igor Erick (2017). Acervo Pepca/Ufopa. 


\section{Considerações teórico-metodológicas}

É notório que arquivos pessoais, enquanto registros memoriais de si e de outrem, podem constituir narrativas eloquentes sobre a vida de um indivíduo ou grupo de indivíduos, informando também sobre os contextos histórico, político e social em que essa vida transcorre (BELLOTO, 2004; BERTONHA, 2007; CUNHA, 2007, 2008; HEYMANN, 1997, 2005; TANNO, 2007; VIDAL, 2007). Todavia, como qualquer outro tipo de fonte, ${ }^{4}$ "[...] o arquivo é sempre o produto de uma linguagem própria, que emana de indivíduos singulares ainda que possa exprimir o ponto de vista de um coletivo" (ROUSSO, 1996, p. 88). Logo, até mesmo arquivos pessoais devem ser interpretados, não se distinguindo dos congêneres institucionais sobre os quais Foucault (1986, p. 149) afirmou que “[...] é preciso conceber os conhecimentos que [os] compõem como um sistema de enunciados, verdades parciais, interpretações histórica e culturalmente constituídas" - o qual está sujeito à leitura e a novas interpretações.

O esforço analítico deve considerar que "[...] no universo dos arquivos pessoais, os documentos do titular compõem-se de inúmeros registros acumulados, cuja função se descola, muitas vezes, dos aspectos informativos imediatos" (LOPEZ, 2003, p. 76). O documento constitui a unidade mínima, uma pequena parcela de informação do arquivo, e precisa ser recolocado no contexto em que ele foi formado por um sujeito específico, em situações históricas e no âmbito de relações sociais determinadas que enquadraram a "[...] ação feita deliberadamente com o intuito de preservar os documentos após o cumprimento das atividades para as quais foram criados" (LOPEZ, 2003, p. 73). Importa, então, captar neles indícios (FRAIZ, 1998) para "entender o produtor dos documentos e não a informação por eles apresentada" (LOPEZ, 2003, p. 73).

A composição de um arquivo pessoal conduz ao problema da subjetividade do colecionador dos documentos, uma vez que estes mantêm relação intrínseca com o passado e a memória do sujeito, indo além do que está fixado no papel e remetendo à ordem do desejo de projeção e construção de uma autoimagem, na medida em que:
[...] arquivar a própria vida é se pôr no espelho, é contrapor à imagem social a imagem íntima de si próprio, e nesse sentido o arquivamento do eu é uma prática de construção de si mesmo e de resistência - arquivar a própria vida é querer testemunhar, é querer destacar a exemplaridade de sua própria vida. (ARTIËRES, 1998, p. 11).

Assim, quando um pesquisador abre uma caixa com documentos, vê apenas os resultados de um processo de seleção que pode ter sido orientado por vários critérios, em diferentes momentos (CASTRO, 2005). Como deslinda Bosi (1994), à materialidade de tais objetos biográficos subjazem processos de cognição, afetividade, intencionalidade, atitude e sentimento de quem os guardou, de modo que se deve "procurar entender a coleção como ato autobiográfico" (BEZERRA DE MENESES, 1998, p. 97).

Diante do baú do Laurimar, as tentativas de compreender cerca de cem documentos íntimos e históricos ali armazenados pautaram a gravação sequenciada de entrevistas e relatos de vida que, visando, simultaneamente, à materialidade dos objetos arquivados e à subjetividade do ato autobiográfico de arquivar, permitiram reconstituir uma trajetória individual na esfera pública.

Inicialmente, cada documento foi higienizado, digitalizado e classificado quanto à tipologia, à cronologia e ao estado de conservação (ruim ou péssimo, na maioria). Em seguida, todos foram descritos por meio de um software gratuito de visualização e conversão de imagem para inserção de metadados. A colaboração de Laurimar nessa etapa foi fundamental: mesmo cego, ele informou sobre a maior parte dos documentos, desde que a equipe os lesse, se escritos, ou os descrevesse, no caso de fotografias e outros elementos visuais. Tamanha colaboração somente foi possível porque um dos pesquisadores desenvolveu com ele uma forte relação de confiança, chegando a se tornar o curador dos objetos pessoais encontrados no baú.

Por muitas vezes fui seus olhos em variadas situações: no próprio museu, quando pessoas chegavam para falar com ele; em sua residência, quando 
precisava identificar algum objeto; nos ambientes a que o levei sendo eu seu guia; em nossos exercícios rotineiros de identificar suas fotografias e documentos pessoais, os quais pacientemente eu descrevia, com detalhes, para que ele pudesse buscar na memória o contexto donde se originava aquela imagem ou documento. (SANTOS FILHO, 2015, p. 29).

Diversas sessões de registro sonoro ou audiovisual dos relatos de vida de Laurimar Leal foram conduzidas por esse mesmo membro da equipe, estreitando-se as relações de confiança e reciprocidade entre entrevistador e entrevistado. Ao fim do trabalho, Santos Filho (2015, p. 29-30) comparou sua experiência à de um "escriba":

Primeiro é necessário ouvir o narrador, aquele que narra o conteúdo a ser abordado pelo pesquisador a fim de formular sua pesquisa. Ao escrever, o pesquisador, amparado pelo aceite de seu narrador, passa a "oficializar" sua memória, e o que era um relato oral torna-se um texto escrito, disposto e estruturado pelo pesquisador; um registro baseado em métodos da sua ciência. Esse texto é um construto no qual a memória se torna documento, e o relato oral, um registro. Assim, realizase a função de escriba do antropólogo.

A maioria das sessões ocorreu no próprio CCJF, onde Laurimar costumeiramente recebia visitantes, amigos e pesquisadores, mas algumas foram realizadas na casa do entrevistado, durante uma reforma do prédio do Centro Cultural. Não havia roteiro predefinido para os registros, e permitia-se que o entrevistado falasse livremente sobre fatos e passagens da vida, conforme a identificação dos documentos os suscitasse. Após um acúmulo significativo de relatos, roteiros para as sessões seguintes foram estabelecidos pelo entrevistador, em comum acordo com o narrador, a fim de completar lacunas, aprofundar detalhes e melhor articular as narrativas, sem, contudo, pretender alcançar a ilusória unidade de uma biografia, já denunciada por Bourdieu (2002), ou a completude de um arquivo "que se exprime pela descontinuidade, pela fragmentação e incoerência" (TANNO, 2007, p. 106).

Laurimar acumulara no baú uma série de objetos e documentos de distintas naturezas com a finalidade de preservá-los, sem necessariamente obedecer a um princípio claro de ordenamento, classificação e agrupamento. Esse não era exatamente um problema, mas uma característica - aliás, comum em arquivos pessoais (HEYMANN, 1997; RIBEIRO, 1998). Acompanhando Herrera (1992, p. 113), pareceu mais adequado tomá-los como um "[...] conjunto, contrapondo-o à ideia de coleção [já que] nunca, em um arquivo, a reunião de documentos se origina de uma proposta arbitrária e subjetiva, segundo critérios apriorísticos".

De fato, o conteúdo do baú era diversificado: títulos, certificados, diplomas, condecorações, correspondências, receitas médicas, fotografias de família, recortes de jornal, recibos, partituras e publicações antigas. Havia também, como já assinalado, insuspeitados registros da trajetória histórica e política do município de Santarém, datados do século XIX e da primeira metade do século subsequente: livros de exposições, relatos de sessões da Câmara Municipal de Santarém, atas de reuniões de prefeitos e administradores distritais do Baixo Amazonas, pareceres do Conselho Municipal e registros do Primeiro Grupo Escolar de Santarém, só para citar alguns exemplos.

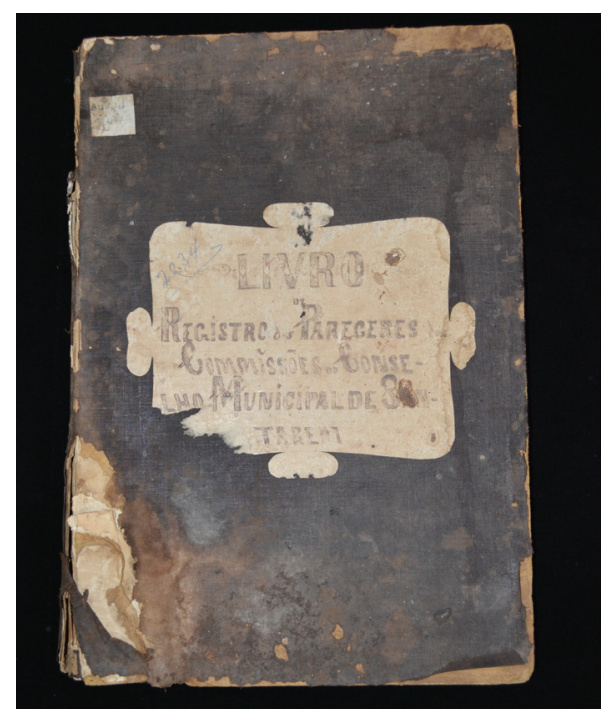

Figura 4: Livro de Registros e Pareceres. Comissões do Conselho Municipal de Santarém.

Fonte: Victoria Ananda Bastos (2012). Acervo Pepca/Ufopa. 
Esse tampouco era um problema, já que a miscelânea de documentos públicos e privados se repete em outros arquivos pessoais, constituindo uma de suas antigas características, conforme expôs Garcia (1998, p. 176-178):

Nos antigos arquivos privados, pessoais ou de família, existiram desde sempre documentos de natureza pública que derivaram de funções, de cargos ou de ofícios públicos [...]. A conservação privada daqueles documentos que hoje se designam como "actos $[$ sic $]$ do Estado" era no passado absolutamente normal [...]. Também nos arquivos privados contemporâneos de personalidades que desenvolveram actividades $[s i c]$ de relevância na administração pública $\mathrm{e}$ na vida política e cultural se encontram documentos pertença do Estado, subtraídos da sua sede natural, para se incluírem nesses papéis pessoais. Nalguns casos esses arquivos pessoais integram, mesmo, séries em falta nos arquivos do Estado.

Mas, se "[...] aquilo que o conjunto documental desse tipo de arquivo expressa está vinculado à construção do personagem a respeito de sua biografia material [,] é esse personagem que origina a lógica da acumulação, o princípio da proveniência de seus guardados" (COSTA, 2007, p. 266). Logo, ao mesmo tempo em que os documentos públicos guardados no baú insinuavam aspectos da atuação de Laurimar à frente do CCJF, as evidências de si - para usar uma expressão de McKemmish (1996) - por ele reunidas conduziam, frequentemente, à vida pública de Santarém. Com suporte dos fragmentos de documentos e esforço do próprio, bem como de um ou outro amigo que se dispôs a testemunhar, ${ }^{5}$ foi possível tecer as tramas inteligíveis de uma vida pública-privada.

\section{Uma trajetória de vida na cultura}

Laurimar dos Santos Leal nasceu em 24 de julho de 1939, filho de Joaquim de Sousa Leal e Julieta Brígida dos Santos Leal. Segundo ele, o pai, de origem marroquina, conferiu-lhe o sobrenome Leal, que "anteriormente era chamado Lael"; da mãe, que "tinha sangue angolano", herdou o sobrenome Santos, que, na origem, teria sido Sarraff (informação verbal). ${ }^{6}$ Laurimar atribui à família a vocação para a arte: "Desde pequeno o pessoal lá em casa mexeu com arte de um modo geral, artesanato, folclore, essas coisas. Por isso que eu sempre me dediquei a isso, pelo costume de família" (informação verbal). ${ }^{7}$ Já à ascendência africana ele remete o gosto pelas danças, rodas de samba, cantigas populares ${ }^{8}$ e outras expressões artísticas que aludem a tradições negras do século XIX. Relembra e canta os versos da dança das Pretinhas d'Angola, que qualifica como produto das "influências da cultura africana" da família.

Nós tínhamos aqui um grupo do qual minha avó fazia parte, chamado as Pretinhas da Angola. As Pretinhas da Angola se reuniam aqui no Urumari [...]. Os negros se reuniam e cantavam: Que preta é aquela que vem aculál É a pretinha da Angola do Urumarizar/ Do Urumarizar, do Urumarizar/ $\bar{E}$ a pretinha da Angola do Urumarizar. Então eu sei todinhas essas coisas, até a maneira de dançar eu sei. Por quê?? Porque minha avó me ensinava. Quando eu era criança, tinha três, quatro, cinco anos, as pretinhas vinham pra dançar lá em casa. E dançavam lá. (informação verbal). ${ }^{9}$

Com nove anos, Laurimar ainda brincava de roda, papagaio e pião, mas teve seu trabalho artístico reconhecido na cidade, quando o então prefeito, Aderbal Tapajós Correa, lhe encomendou placas para as mesas da prefeitura. Nesse tempo, ele já se ocupava na produção de cerâmica para o presépio de natal da família, junto com o amigo Renato Sussuarana, artista renomado que criou obras monumentais na região. A educação primária e a iniciação em artes ocorreram em casa, com o amparo das tias Raquel e Judite.

Quando eu fui para a escola mesmo, eu não fui para a turma $C$, que era a mais atrasada. Eu fui para a B, turma $B$, depois turma $A$, que era relativo ao primeiro ano, depois segundo, terceiro... Minha primeira escola, quando eu saí de casa, foi o barracão de São Raimundo Nonato, em 1948, que ficava lá onde hoje é a praça. Eu ia daqui da 
Galdino Veloso com minha tia Raquel. Depois do barracão de São Raimundo, eu fui estudar na Sociedade Artística Beneficente de Santarém, que ficava na Rui Barbosa, bem em frente à rua João Otaviano de Matos. Quando eu saí de lá, eu fui para onde hoje é o teatro Vitória. (informação verbal). ${ }^{10}$

Mais tarde, Laurimar foi para a Escola Isolada $^{11}$ Masculina Professora Ilda de Almeida Mota para ter aulas com a própria madrinha, que dava nome ao estabelecimento. Estudou no Colégio Magalhães Barata (hoje Álvaro Adolfo da Silveira); depois, no Grupo Escolar de Santarém (atual colégio Frei Ambrósio); por fim, no Seminário Franciscano de Ipuarana, em Campina Grande, na Paraíba. Para lá, foi a cargo dos frades franciscanos; então, teve oportunidade de aprofundar-se em estudos de música, latim e língua inglesa, além de produzir suas primeiras telas: "Lá eu usei tinta e comecei a pintar meus quadrozinhos, as primeiras telas" (informação verbal). ${ }^{12}$

Retornando a Santarém, entre 1958 e 1959, fez a primeira exposição de pinturas, no Colégio Dom Amando, considerado o melhor da cidade. Nos anos 1960, migrou para o Rio de Janeiro, a convite de um grupo de antigos amigos de escola que já estavam morando naquela cidade. Estudou arte, pintura, produziu intensamente e fez amizade com os renomados Roberto Burle Marx (19091994), paisagista, e Joãozinho Trinta (1933-2011), carnavalesco. Enfrentou dificuldades financeiras, desempregado:

No Rio de Janeiro eu recordo muito bem, porque eu passei pedaços difíceis. A princípio, eu não estava trabalhando $e$ tinha dificuldades de arranjar dinheiro. Eu fazia meu almoço, meu café e meu jantar numa casa onde se vendia comida para os estudantes. Pagava-se um real por prato. Então, eu comia lá. Nós chamávamos a casa de Calabouço. O Calabouço ficava no centro da cidade, mas bem dizer assim na orla, após o Flamengo. Então, eu almoçava por lá e morava na Marquês de Abrantes, que é Flamengo. Até que eu arranjei emprego numa loja lá, que se chamava Cássio Muniz. Eu fui pra lá e comecei fazer vitrina. (informação verbal). ${ }^{13}$
Depois de deixar a loja, Laurimar foi para as ruas da cidade, onde passou a expor telas e retratos em frente ao Teatro Municipal, “[...] riscando no papel, na cartolina, e vendendo [...]. Eu cheguei a dormir na rua e ficava desenhando o rosto das pessoas pra ganhar algum dinheiro" (informação verbal). ${ }^{14}$ Assim passou, até que recebeu ajuda de um desconhecido.

Depois eu fui morar em um bairro que era atrás do Oswaldo Cruz, aquele instituto. Fui pra lá e continuei fazendo trabalhos. Até que um dia eu estava lá na praça, e apareceu um tenente do Exército e perguntou onde eu morava. Eu disse pra ele onde eu morava e ele disse: 'Ah, tu não queres vir morar aqui perto?' Eu perguntei: Onde? Ele me disse: 'Aqui na..., quem vai para Santa Tereza. É aqui perto". Eu disse: Ah, eu quero! Aí ele me levou para morar lá em Santa Tereza. (informação verbal). ${ }^{15}$

Apareceram outras possibilidades de emprego e moradia, e Laurimar mudou-se para o bairro de Copacabana, então em vias de expansão e enobrecimento, e passou a ter uma rede de contatos com pessoas do circuito artístico carioca, entre elas Clóvis Bornay, Evandro de Castro Lima e Joãozinho Trinta, ${ }^{16}$ com quem aprendeu a confeccionar fantasias carnavalescas. Ainda no Rio, inscreveuse em um concurso de calouros promovido pela Rádio Nacional: "Eu peguei e meti a cara, e ganhei o concurso de calouros. Aí eles me deram dinheiro e me deram uma bolsa de estudos de canto". Assim, Laurimar passou a frequentar a escola de canto, e logo descobriu, nos seus arredores, a Escola de Artes da Praia Vermelha: "Aí eu meti a cara na escola de artes" (informação verbal). ${ }^{17}$

Tantas experiências conferiram a Laurimar um cabedal de conhecimentos que, mais tarde, ele poria em prática em Santarém. O retorno para a terra natal foi mediado por "uma distinta senhora da sociedade santarena, chamada Guilda Guimarães", professora e irmã de um ex-deputado federal, que, não gostou de vê-lo trabalhando como artista de rua no Rio de Janeiro e recorreu a políticos para o trazerem de volta (informação verbal). ${ }^{18}$ 
O prefeito nessa época era o Everaldo de Sousa Martins. Ele disse que iria mandar me buscar. E ele mandou passagem, mandou tudo. Foi por isso que eu vim embora do Rio para cá para Santarém. Mas durante o tempo todo que eu estive no Rio, eu trabalhava com arte. (informação verbal). ${ }^{19}$

A volta para casa ocorreu entre 1966 e 1967, provocando mudanças na vida pessoal a partir da aproximação com o poder público, que lhe conferiu a missão de promover a cultura local. Logo se tornou diretor de arte na fábrica Tecejuta - Cia. de Fiação e Tecelagem de Juta de Santarém, comandando a seção de artesanato e pintura. Segundo conta: "[...] usávamos a técnica macramê, que dava possibilidade de fazer chapéus, quadros, tecidos, tudo manual, criando peças para exportar para o Japão principalmente, especialmente painéis feitos com barras em tecido de juta, com pinturas da região". ${ }^{20} \mathrm{Em}$ 1969, recebeu menção honrosa da Rádio Educadora de Santarém, ligada ao Movimento de Educação de Base, que era responsável por aulas radiofônicas em dezenas de comunidades e pela da Feira da Cultura Popular de Santarém (SANTOS, 1999).

Depois, ocupou um cargo na Prefeitura, tornando-se o responsável pela programação de atividades artísticas e culturais, até então pouco estimuladas na cidade. Em 1972, o artista alcançou projeção na "Semana de Santarém", realizada em Belém. Segundo conta, vendeu toda a coleção de painéis que expôs na galeria Ângelus, no Teatro da Paz. O êxito do evento foi celebrado na imprensa local, que exaltou a presença da cultura santarena em um local nobre na capital.

Poesia... Música...Pintura... Artesanato... Folclore... Sempre o tivemos, e esses tesouros espirituais vieram à luz da consagração pública, de uma só vez, há três anos, quando no "Teatro da Paz", em nossa capital se promoveu a “SEMANA DE SANTARÉM”. Durante cinco noites, a deslumbrante catedral da arte esteve inteiramente lotada por plateias que, surpresas e embevecidas ante as lindezas vistas e escutadas extravasavam seu encanto na linguagem universal das palmas vibrantes e das lágrimas silenciosas. Era a verdadeira alma santarena emergindo, em toda sua esplêndida grandeza no suntuoso palácio, de tão formosa ribalta! (BEMERGUY, 2010, p. 46, grifos no original).

Durante o mandato do prefeito Paulo Lisboa (1975-1978) Laurimar começou a confeccionar esculturas monumentais nas principais praças da cidade: a do Padre Felippe Bettendorff, na Praça Rodrigues dos Santos; a do negro liberto, na Praça da Liberdade; e aquelas inspiradas em vasos da cultura tapajônica, na Praça São Sebastião.

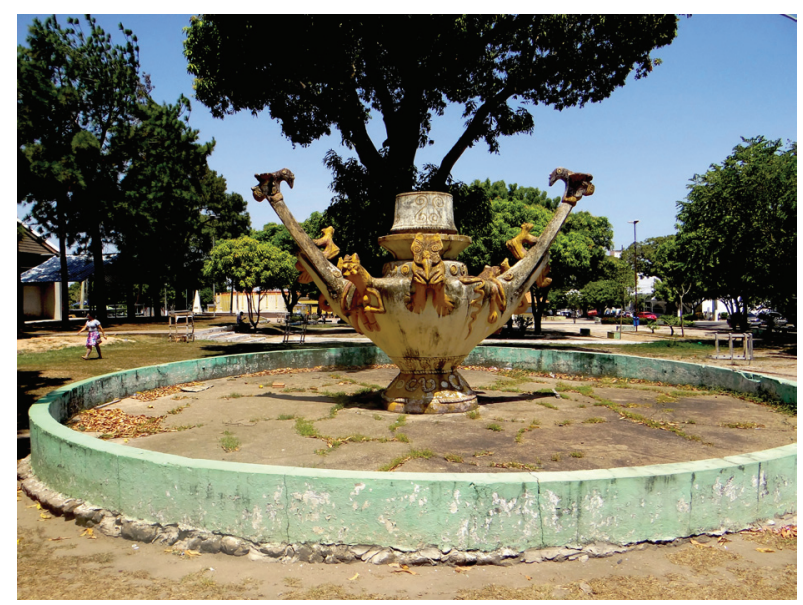

Figura 6: Escultura na praça São Sebastião

Fonte: Igor Erick (2017). Acervo Pepca/Ufopa.

No mesmo período, no Centro Social Urbano, aconteceu uma edição do concurso Miss Santarém. Segundo sua amiga Eliete Amazonas, concorrente pelo Colégio Almirante Soares Dutra, Laurimar preparou algo considerado originalíssimo para a ocasião: cobriu o corpo de sua candidata com purpurina, que já era largamente usada em discotecas e desfiles carnavalescos no Rio de Janeiro, mas praticamente desconhecida em Santarém.

Eu lembro que a menina que representava a agremiação dele era a Conceição. Naquela época, quase ninguém ouvia falar em purpurina, não sabíamos o que era. Aí ele jogou um óleo sobre o corpo dela e soprou aquele pó colorido por todo o seu corpo. E ele fez isso tudo em segredo, dizendo que tinha um trunfo na mão. E valeu a pena, porque ela foi 
a campeã e o trabalho ficou muito lindo. (informação verbal). ${ }^{21}$

O Rio, com sua vida noturna e efervescência artística e cultural, era o modelo de criatividade e modernidade a partir do qual Laurimar proporia inovações na cultura regional. Inspirado no que vira na cidade, fundou a Ases do Samba, primeira escola de samba de Santarém; e, em seguida o conjunto Os Brasas, que tocava música popular brasileira e regional: "Os Brasas era um dos primeiros conjuntos eletrônicos de Santarém, do qual Ray Brito, Walter Brito, eu e outras pessoas éramos os crooners. Eu era $o$ dono do conjunto" (informação verbal). ${ }^{22}$

A década de 1980 viu crescer o carnaval em Santarém. Laurimar passou a promover exibições de fantasias em clubes frequentados pelas elites, tal qual no Rio de Janeiro. As agremiações aprimoravam-se a cada ano para os desfiles na Avenida Barão do Rio Branco, que ele e o amigo Sussuarana ornamentavam, aplicando inovações estéticas a elementos regionais, em luxuosos enfeites: "Trabalhávamos temas regionais para a ornamentação. O nosso grupo, Ases do Samba, descia a avenida também. Era lindo poder ver aquelas borboletas grandes enfeitando as laterais da avenida, as plantas e os pássaros. O povo adorava". ${ }^{23}$ A elite intelectual da cidade, representada pelo escritor Emir Bemerguy (2010, p. 93), também festejava as inovações modernizantes que traziam a Santarém "uma autêntica escola de samba", a qual receberia da Câmara Municipal o título de Honra ao Mérito.

[...] na primeira vez em que os santarenos se deslumbraram com a luxuosa e original "Ases do Samba", algo fora de série aconteceu. Aí pelas oito e meia da noite da Terça-feira Gorda, recebo um recado urgente: "Laurimar manda avisá-lo que dentro de quinze minutos a escola 'Ases do Samba' vai passar defronte de sua casa". Vesti uma roupa menos debochada que o pijama e fiquei à porta, esperando. E lá vêm os batuqueiros, fazendo tremer o chão de minha rua! Um esplendor de bom gosto e criatividade [...]. Pela primeira vez na vida, fora da televisão, eu via uma autêntica Escola de Samba. E desfilando só pra mim!... Cada uma das alas ficava fazendo graciosas evoluções à minha frente, até que o líder mandasse a seguinte aproximar-se. Uma honra! Assombrava-me ao saber que todas as fantasias lindas e invulgares tinham sido inventadas pelo fabuloso Laurimar Leal. Também eram obras suas os demais detalhes - desde as alegorias de mão às figuras que representavam os pormenores do enredo. (BEMERGUY, 2010, p. 93).

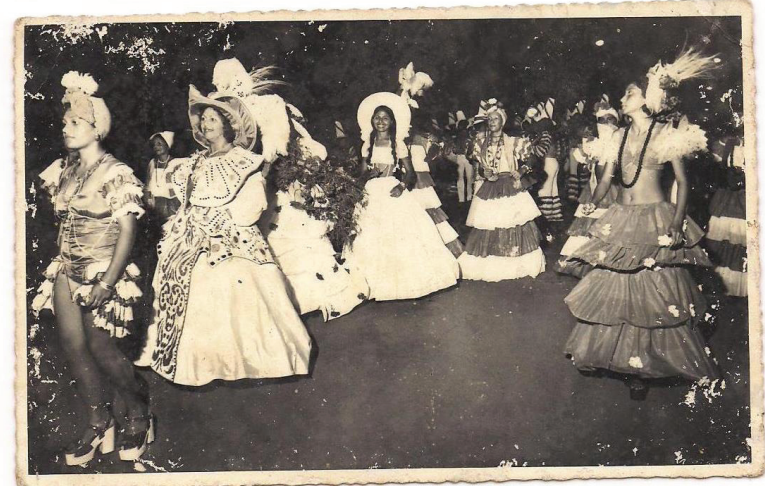

Figura 7: Carnaval em Santarém

Fonte: Arquivo pessoal de Laurimar Leal.

Em 1984, a municipalidade conferiu a Laurimar sua mais alta condecoração, a medalha Padre João Felipe Bettendorf, instituída pela Lei $\mathrm{n}^{\circ}$ 9.386/81. Em 1986, o prefeito em exercício designou-o para organizar o $1^{\circ}$ Festival Folclórico do Médio Amazonas. Ainda em meados dos anos 1980, ele participou da criação do CCJF, cujo embrião foi concebido a partir da sua iniciativa de, juntamente com uma equipe, montar um museu de pequeno porte nas dependências da Casa de Cultura Historiador João Santos, com coleções de cerâmicas arqueológicas doadas por particulares e pelo Banco da Amazônia. A instituição foi reinaugurada em 1987, abrigando a chamada Galeria de Arte, com três salas para exposição permanente. No mesmo ano, ele recebeu da Câmara Municipal de Santarém o título de Honra ao Mérito.

Laurimar era ciente do valor cultural daquelas coleções capazes de atrair pesquisadores como Anna Roosevelt, que chegou a conhecer por força do interesse comum no material arqueológico. Também vislumbrava, como poucos em seu tempo, a importância da preservação desse patrimônio 
para a inserção da região no cenário nacional e internacional. Assim, em 1990, foi nomeado diretor da Casa de Cultura, onde idealizou o projeto de implantação de um museu de médio porte, já que a casa " $n$ ão tinha reserva técnica nem sala de exposição temporária, nem sala para reuniões" (informação verbal). ${ }^{24}$

O novo museu foi implementado sob sua gestão em um imóvel recém-restaurado na praça São Sebastião, que foi dividido com a Prefeitura até 1991, quando foi destinado exclusivamente para o CCJF. Em seguida, Laurimar assumiu a Secretaria Municipal de Cultura, Desporto e Turismo, e, em 1993, tornou-se chefe da Divisão de Cultura da mesma secretaria, além de membro do Conselho Municipal de Cultura. Em 1994 foi nomeado chefe da sessão de Administração de Equipamentos Culturais e, em 1997, chefe da Seção de Artes da Divisão de Cultura da Coordenadoria Municipal de Cultura. Ainda nos anos 1990, Laurimar fundou a Escola de Arte de Santarém, que, segundo sua colega Ana Leal, formou "vários artistas que hoje são famosos na cidade" (informação verbal). ${ }^{25}$

Paralelamente a esses feitos, Laurimar realizou trabalhos aos quais atribui grande valor sentimental: pinturas temáticas no interior de igrejas, esculturas e restauros de santos, intervenções paisagísticas e design de altares. Entre outras, a catedral da matriz de Nossa Senhora da Conceição e a igreja de São Raimundo Nonato, em Santarém, além da catedral de Rurópolis, receberam de Laurimar painéis e imagens restauradas. A igreja de Santo Inácio de Loyola, no distrito santareno de Boim, ganhou dele a pintura do altar-mor. Para pelo menos dois terreiros de candomblé em Santarém (Ilê Dara Asê Oyá Onira e Ilê Axé Ogumjaodé) Laurimar também produziu esculturas.

Por 15 anos, a convite de Frei Paulo Zoderer, ele e sua amiga Maria das Graças Ferreira (Dicita) foram encarregados da preparação do manto que cobre a imagem (que ele também reformou) da padroeira, Nossa Senhora da Conceição, durante o círio que acontece no final de novembro em sua homenagem. ${ }^{26}$ Ambos também ajudavam a ornamentar a berlinda, procurando combinar o manto com o conjunto da peça. Hoje, alguns dos mantos que criaram estão expostos no museu de Arte Sacra de Santarém.

Da década de 1990 até a primeira dos 2000 Laurimar ofereceu diversos cursos na Universidade Federal do Pará, na Universidade Luterana do Brasil, no Instituto Santareno de Ensino Superior. Ministrou oficinas no Serviço de Aprendizagem Comercial de Santarém, na Fundação Esperança de Santarém e em escolas públicas e privadas. Proferiu inúmeras palestras nas cidades de Monte Alegre, Alenquer, Oriximiná e Belém. Recebeu, ainda, congratulações, certificados de honra ao mérito, moções de aplausos da Câmara Municipal de Santarém e da Assembleia Estadual do Pará, além do reconhecimento de instituições como o Rotary Clube, a Ação em Medicina Internacional (AIM) e a Companhia SOL 3, que o levou à França em missão de pesquisas em 1995.

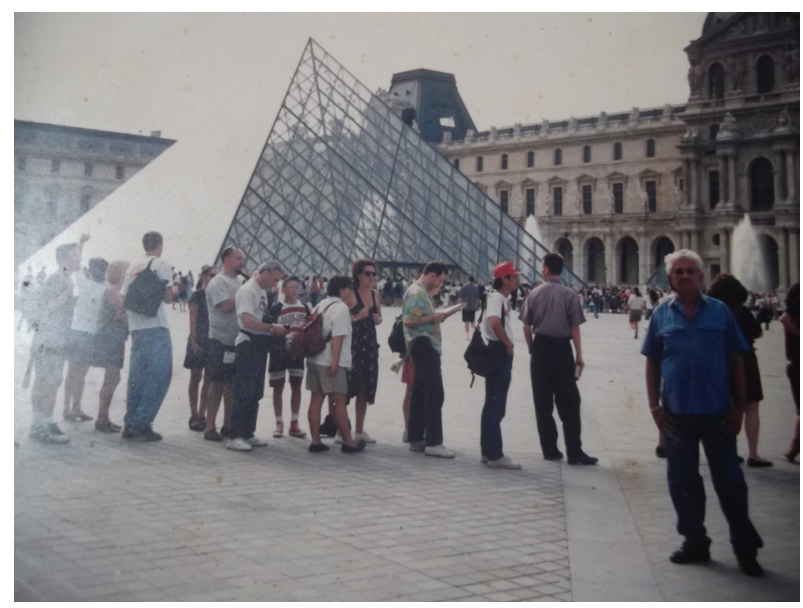

Figura 8: Laurimar no Museu do Louvre, Paris, França Fonte: Arquivo pessoal de Laurimar Leal (1995).

Laurimar frequentou festas de famílias tradicionais de Santarém e ocupou uma sucessão de cargos públicos ligados à promoção e à administração da cultura. Adquiriu prestígio e reconhecimento nas fases mais férteis de produção artística-cultural, fazendo carreira como artista e homem público. Como tal, exerceu a faculdade de transitar por todos os meios sociais. Do candomblé ao catolicismo, dos pobres aos ricos, atendia a inúmeros pedidos que lhe chegavam e lhe davam a honra que gostava de ter.

Porém, com o passar do tempo, Laurimar conheceu o mesmo processo relatado por Carvalho 
(2014, p. 218) em outro caso: "[...] a experiência do envelhecimento biológico veio acompanhada da gradual desarticulação do papel social desempenhado com relativo sucesso e orgulho desde a juventude". Aos poucos, caminhou para um estágio de esquecimento e abandono, ou de morte social, nos termos de Elias (2001), como o próprio Laurimar reconhece:

\begin{abstract}
As pessoas não sabem buscar o que é nosso pra valorizar nossa terra. Pelo contrário, buscam as coisas de fora, e a gente vai ficando como se nunca tivesse existido. Eu mesmo, ninguém mais me procura pra saber das coisas. Acham que cego não sou capaz mais de fazer nada. Mas eu quero te dizer que eu posso usar a cabeça e o coração pra muitas coisas. (Informação verbal). ${ }^{27}$
\end{abstract}

A partir de 2005, depois de uma crise de glaucoma que o privou da visão, Laurimar foi gradativamente isolado das esferas decisórias no campo da cultura. Restou-lhe apenas o banco do CCJF como domínio onde ainda encontrava prestígio e honraria atribuídos por alguns amigos, pesquisadores e visitantes que o viam, irônica ou carinhosamente, como mais uma "peça do museu", ainda que ocupasse a posição de diretor da casa. ${ }^{28}$

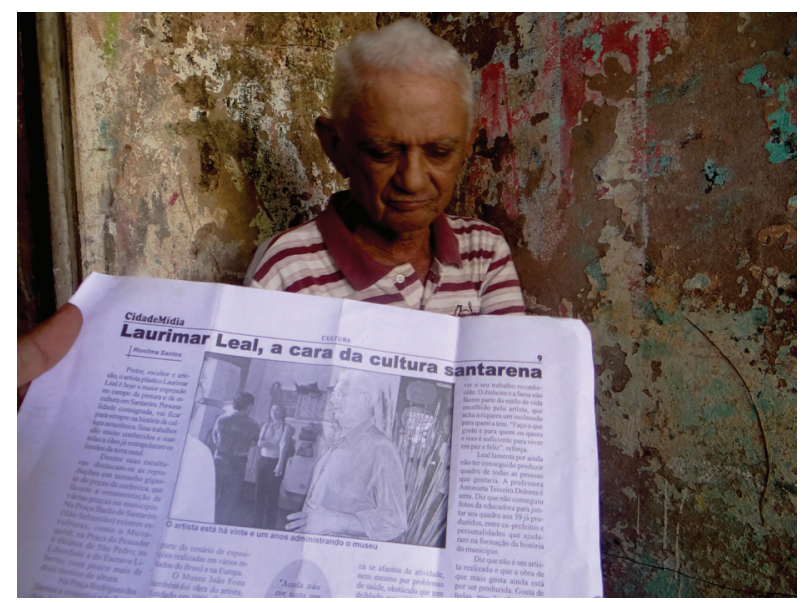

Figura 9: Laurimar Leal em matéria jornalística Fonte: Igor Erick (2017). Acervo Pepca/Ufopa.

Em 2014, com o início de uma reforma do imóvel, Laurimar foi removido da direção do CCJF e, por conseguinte, da vida pública. Abalado pela idade avançada, pela cegueira, por desafetos e críticas de profissionais ligados a museus e outros espaços culturais quanto ao estado do acervo do centro e à sua gestão, ${ }^{29}$ recolheu-se em casa e passou a nutrir planos de instalar um museu a céu aberto na propriedade que detém no bairro do Maicá, na zona periurbana de Santarém. Para o espaço, Laurimar projeta um memorial da cultura santarena, que avalia como carente de reconhecimento e valorização.

Olha, o meu projeto trata-se de um museu a céu aberto onde se mexa com lendas, mitos, costumes e tradições. Eu não quero que a coisa mude e o povo se esqueça dos nossos costumes, das nossas lendas, das nossas tradições e dos nossos mitos. É por isso que eu quero fazer lá no Maicá um museu a céu aberto, onde tenha, na floresta, embaixo de certas árvores, algumas esculturas de coisas nossas, como a Yara, a Matinta Pereira, o Mapinguari [...]. Então, é bom que a gente cuide do que é nosso. Por exemplo, fazer uma casa de farinha pra se saberem como é que se faz farinha, e nesse meio contar a lenda da mandioca, que é nossa mandioca. E pessoas. Falar sobre pessoas do nosso povo aqui. Porque, se nós não dermos atenção, o tempo passa e vai se perder a memória da pessoa que existiu aqui. (informação verbal). ${ }^{30}$

Portador de uma criatividade vigorosa que o corpo já não respeita, Laurimar ainda nutre o sonho de criar um espaço destinado à "promoção da memória do nativo, com seus mitos, histórias e objetos", mas seus desejos parecem não mais corresponder aos planos institucionais vigentes no campo da cultura em Santarém.

\section{Considerações finais: o que o baú de Laurimar revela sobre a cultura em Santarém}

A história de vida de Laurimar dos Santos Leal se confunde com a história de um campo cultural que se conformou a partir de fins da década de 1960, consolidando-se nos anos 1990, em Santarém, com influência em toda a região. Ao longo da trajetória desse homem que, com auxílio do poder público local, alcançou prestígio 
como artista plástico, compositor, carnavalesco, restaurador, mestre, colecionador, curador de exposições e administrador cultural, fica claro que o público e o privado assumem distinções tênues, rejeitando qualquer dicotomia.

Não se pretendeu, aqui, realizar a biografia de Laurimar Leal, tampouco esgotar as possibilidades de exploração dos documentos encontrados em seu baú. Reconstituir e fixar memórias em suportes diversos é prática histórica de determinados indivíduos e grupos sociais - sobretudo dos chamados homens de letras, que formam arquivos pessoais a partir de vários documentos e papéis (CHARTIER, 1996). O baú de Laurimar é um arquivo dessa natureza, que suscita múltiplas possibilidades investigativas merecedoras de atenção nos campos da história e da antropologia.

Inesperadamente, em 2011, esse pequeno e velho móvel abriu sua tampa para um universo rico e fascinante que podia ser percorrido com o auxílio dos documentos de uma coleção cuja trajetória nem o dono foi capaz de reconstituir. Talvez Laurimar pressentisse o encerramento próximo de sua vida pública como administrador de cultura em Santarém, que viria a ocorrer em 2014, com seu afastamento da direção do CCJF. Talvez quisesse, pelo pressentimento, assegurar melhor condição de guarda e organização de sua coleção.

Diante de um sujeito que, nos documentos reunidos, fez de si uma representação que pretendeu guardar para si e para os outros, ter acesso aos seus relatos orais e biográficos foi essencial para a compreensão do quanto aquele conjunto documental pode "falar" de seu dono. São inegáveis nesse conjunto, como aponta Ribeiro (1998, p. 35 , grifo do original), "[...] o desejo de perpetuarse [...] e [o] anseio de forjar uma glória [...] e ser reconhecido pela posteridade por uma identidade digna de nota".

$\mathrm{Na}$ oportunidade de ler as linhas e entrelinhas dos documentos e dos relatos biográficos de Laurimar, não se poderia deixar de reter que aspectos da vida privada desse sujeito são pistas importantes e esclarecedoras sobre processos sociais mais abrangentes. Sem dúvida, a história de vida narrada por Laurimar ilumina aspectos relevantes para a compreensão do campo da cultura em Santarém. Acompanhando-o, percorremos o espaço urbano da segunda metade do século XX, as transformações do carnaval e a organização de movimentos culturais na cidade, bem como a formação de um espaço público para salvaguardar coleções de arte e artefatos arqueológicos onde, até então, não havia museus.

Tudo isso se revelou a partir do velho baú do Laurimar, hoje guardado em casa entre obras de arte de sua lavra e outros objetos acumulados ao longo da vida. O móvel estava pleno de objetos biográficos que representam experiências vividas e afetivas do portador. Nesse sentido, o próprio CCJF, onde ficava o baú, era um objeto biográfico de Laurimar: o lugar que conectava intimamente o público e o privado em sua vida. O centro era a casa, no sentido dado por Da Matta (1991), cujos detalhes se lhes mostravam nítidos apesar da cegueira.

Os domínios do privado e do público, do indivíduo e da sociedade, confundem-se na experiência e na narrativa do sujeito, e as interseções entre eles permitem entrever aspectos do processo de institucionalização do campo da cultura em Santarém. Aliás, na representação que faz de si, Laurimar confunde-se com a própria "cultura", incorporando à sua a memória da instituição, que, conforme Douglas (2007, p. 116),

[...] começa a controlar a memória de seus membros; ela os leva a esquecer experiências incompatíveis com aquela imagem de correção que eles têm de si mesmos e traz para suas mentes acontecimentos que apoiam uma visão da natureza que lhe é complementar. A instituição propicia as categorias dos pensamentos de seus membros, estabelece os termos para o autoconhecimento e fixa as identidades.

O campo da cultura em Santarém também incorpora as memórias individuais de Laurimar à sua, reconhecendo o emaranhado de suas trajetórias. Por isso, ele tornou-se digno de receber uma pensão vitalícia da prefeitura, revestida de alto valor simbólico, desde que a cegueira o atacou. Em sua trajetória, Laurimar experimentou o mundo fora de Santarém, o que lhe conferiu concepções 
particulares de projetar como a cultura local deveria ser, forjando conceitos para se referir a ela como um ato de "cuidar do que é nosso", como sempre diz, evocando especificamente o campo se construiu como sujeito.

\section{Notas}

$1 \mathrm{O}$ nome oficial da praça é Barão de Santarém, já tendo sido chamada praça da Municipalidade e Municipal.

$2 \mathrm{O}$ trabalho fora concebido no âmbito de um programa de pesquisa e extensão voltado à preservação do patrimônio cultural regional, que já havia inventariado os artefatos arqueológicos e documentos históricos guardados no CCJF. Sua equipe era formada por: um docente de Antropologia, duas cursistas do ensino médio, dois graduandos em Antropologia e duas graduandas em Letras, que eram também fotógrafas, além de uma pósgraduanda em Direitos Humanos e Políticas Públicas.

3 No plano internacional, a institucionalização do campo da cultura tem na França um marco histórico correspondente à criação, em 1959, do Ministério de Assuntos Culturais, cujas ações se tornaram referências para muitos países ocidentais (CALABRE, 2007). Com efeito, Bolán (2006) demonstra que, desde o Renascimento, a originalidade do caso francês no que tange ao estabelecimento de políticas públicas de arte e cultura fez dessa nação um "modelo de civilisación" para muitos outros povos.

4 Rousso (1996) insiste na necessidade de estabelecer a noção de fonte e de relativizar o seu valor de prova como ponto de partida para a compreensão da natureza da pesquisa em arquivos. No mesmo sentido, Prochasson (1998, p. 112) exige "romper a inevitável relação afetiva que se estabelece entre o historiador e seu material epistolar" por meio da objetivação desse material e sua construção como fonte.

5 Segundo Halbwachs (2006, p. 29), “[...] recorremos a testemunhos para reforçar ou enfraquecer e [...] completar o que sabemos de um evento sobre o qual já temos alguma informação, embora muitas circunstâncias a ele relativas permaneçam obscuras [...]". No caso, a reconstituição de histórias de vida de Laurimar Leal contou, eventualmente, com apoio de amigos que se dispuseram a ver materiais contidos no baú a fim de elucidá-los e/ou complementar informações deixadas em aberto por ele.

6 Entrevista concedida por Laurimar Leal a Osinaldo Santos Filho em 08 de agosto de 2012, na qual ele relembra que os judeus, ao se converterem ao cristianismo, tinham seus nomes alterados, sem, contudo esclarecer sobre a origem judia de seus pais.

7 Entrevista concedida por Laurimar Leal a Osinaldo Santos Filho em 08 de agosto de 2012.
8 Interpretações musicais de Laurimar estão disponíveis em: https://fabiocavalcante.com/discos/musicas-dedominio-publico-do-folclore-santareno/. Acesso em: 10 ago. 2019.

9 Entrevista concedida por Laurimar Leal a Osinaldo Santos Filho em 19 de dezembro de 2012.

10 Entrevista concedida por Laurimar Leal a Osinaldo Santos Filho em 10 de agosto de 2012.

11 As escolas isoladas se multiplicaram no interior do Brasil na primeira metade do século XX, com a missão de oferecer ensino básico a alunos de diversas idades, geralmente atendidos por um único docente leigo.

12 Entrevista concedida por Laurimar Leal a Osinaldo Santos Filho em 08 de agosto de 2012.

13 Entrevista concedida por Laurimar Leal a Osinaldo Santos Filho em 10 de agosto de 2012.

14 Entrevista concedida por Laurimar Leal a Osinaldo Santos Filho em 13 de agosto de 2012.

15 Entrevista concedida por Laurimar Leal a Osinaldo Santos Filho em 13 de agosto de 2012.

16 Clóvis Bornay (1916-2005) foi um personagem de renome na cena cultural carioca, onde trabalhou como museólogo no Museu da República e no Museu Histórico Nacional, carnavalesco em diversas escolas de samba e mestre de fantasias de carnaval. Idealizador do Baile de Gala do Teatro Municipal do Rio de Janeiro, inspirado nos bailes de Veneza, foi também ator, cantor, pesquisador, professor, organizador de exposições, agitador cultural e militante do movimento LGBT. O baiano Evandro de Castro Lima (1920-1985), apesar de formado em Direito, fez fama como figurinista, bailarino, carnavalesco e concorrente de Bornay nos concursos de fantasias. Por fim, o maranhense Joãosinho Trinta (1933-2011) chegou ao Rio de Janeiro em 1957 para estudar dança no Teatro Municipal, cujo corpo de baile integrou. Em 1961, começou a carreira em grandes escolas de samba cariocas, ganhando diversos títulos. Com o lema: "O povo gosta de luxo. Quem gosta de miséria é intelectual", levou luxo, brilho e riqueza aos desfiles.

17 Entrevista concedida por Laurimar Leal a Osinaldo Santos Filho em 13 de agosto de 2012.

18 Conforme Da Matta (1991), a rua é um espaço associado ao perigo, à impessoalidade e à malandragem na sociedade brasileira, e o Rio era uma capital famosa pelo cosmopolitismo e a boemia, cujo universo moral se chocava com o do interior do Pará, onde Laurimar circulava entre famílias de elites e instruídas.

19 Entrevista concedida por Laurimar Leal a Osinaldo Santos Filho em 13 de agosto de 2012.

20 Entrevista concedida por Laurimar Leal a Osinaldo Santos Filho em 14 de abril de 2015. O macramê, a que ele se refere, é um tipo de tecelagem em que fios são cruzados e atados em nós, gerando formas geométricas e franjas. 
21 Entrevista concedida por Eliete Amazonas a Osinaldo Santos Filho em 10 de agosto de 2014.

22 Entrevista concedida por Laurimar Leal a Osinaldo Santos Filho em 13 de agosto de 2012.

23 Entrevista concedida por Laurimar Leal a Osinaldo Santos Filho em 14 de abril de 2014.

24 Entrevista concedida por Laurimar Leal a Osinaldo Santos Filho em 11 de dezembro de 2012.

25 Entrevista concedida por Ana Leal a Osinaldo Santos Filho em 14 de dezembro de 2012.

26 Os círios são procissões que ocorrem em todo o Pará, sendo famoso o de Nossa Senhora de Nazaré.

27 Entrevista concedida por Laurimar Leal a Osinaldo Santos Filho em 18 de fevereiro de 2014.

28 Laurimar ainda era, oficialmente, diretor da casa mantida pela prefeitura, mas suas condições não permitiam que exercesse plenamente a função, tornandose dependente de outros funcionários.

29 Santarém tem crescido significativamente nos anos 2000, de modo a firmar-se como polo econômico e cultural da região do Baixo Amazonas. Além de reunir várias Organizações Não Governamentais, com especialistas de diversas áreas, a cidade tem atraído e qualificado profissionais com alto nível de instrução e experiência desde que se tornou sede de uma universidade federal, em 2010. Em relação ao CCJF, eles cobram, entre outras, medidas de adequação do espaço a normas técnicas, profissionalização da gestão e recomposição do corpo funcional com base em critérios técnico-científicos, em detrimento das relações políticas e pessoais mantidas com determinados segmentos.

30 Entrevista concedida por Laurimar Leal a Osinaldo Santos Filho em 14 de dezembro de 2012.

\section{Referências}

ARTIÈRES, Philippe. Arquivar a própria vida. Estudos Históricos, v. 11, n. 21, p. 9-34, 1998.

BELLOTO, Heloísa. Arquivos permanentes: tratamento documental. Rio de Janeiro: FGV, 2004.

BEMERGUY, Emir. Santarenices: coisas de Santarém. Santarém: Instituto Cultural Boanerges Sena, 2010.

BERTONHA, João Fábio. A construção da memória através de um acervo pessoal: o caso do fundo Plínio Salgado em Rio Claro (SP). Patrimônio e memória, v. 3, n. 1, p. 112-120, 2007.
BEZERRA DE MENESES, Ulpiano Toledo. Memória e cultura material: documentos pessoais no espaço público. Estudos Históricos, v. 11, n. 21, p. 89-103, 1998.

BOLÁN, Eduardo Nivon. La política cultural: Temas, problemas y oportunidades. México: Conaculta/Fonca, 2006.

BOSI, Ecléa. Memória e sociedade: lembranças de velhos. São Paulo: Cia das Letras, 1994.

BOURDIEU, Pierre. A ilusão biográfica. In: AMADO, Janaína; FERREIRA, Marieta. Usos e abusos da história oral. Rio de Janeiro: Fundação Getúlio Vargas, 2002. p. 183-191.

CALABRE, Lia. Políticas Culturais no Brasil: balanço e perspectivas. III ENECULT - Encontro de Estudos Multidisciplinares em Cultura, 2007.

CARVALHO, Luciana Gonçalves de. Posfácio. In: CARVALHO, Luciana Gonçalves de. Cadernos de Betinho: um Pai Francisco e sua missão no bumba meu boi maranhense. Santarém: Cumbuca, 2014. p. 195-225.

CASTRO, Celso. A trajetória de um arquivo histórico: reflexões a partir da documentação do Conselho de Fiscalização das Expedições Artísticas e Científicas no Brasil. Estudos Históricos, Rio de Janeiro, n. 36, p. 33-42, 2005.

CHARTIER, Roger. L'homme de lettres. In: VOVELLE, Michel (Org.). L'homme des Lumières. Paris: Éditions du Seuil, 1996. p. 159-209.

COSTA, Tati Lourenço da. Três atos para escrever sobre a vida. $\mathrm{O}$ arquivo de fotografias de Armínio Kaiser. Patrimônio e memória, v. 9, n. 2, p. 257282, 2007.

DA MATTA, Roberto. A casa e a rua. Rio de Janeiro: Guanabara Koogan, 1991.

DOUGLAS, Mary. Como as instituições pensam. São Paulo: Editora Universidade de São Paulo, 2007.

ELIAS, Norbert. A solidão dos moribundos. Rio de Janeiro: Jorge Zahar, 2001. 
FOUCAULT, Michel. O enunciado e o arquivo. In: FOUCAULT, Michel. A arqueologia do saber. Rio de Janeiro: Forense Universitária, 1986. p. 87-150.

CUNHA, Maria Teresa S. Do baú ao arquivo: escritas de si, escritas do outro. Patrimônio e memória, v. 3, n. 1, p. 45-62, 2007.

CUNHA, Maria Teresa S Essa coisa de guardar... Homens de letras e acervos pessoais. História da Educação, v. 12, n. 25, p. 109-130, 2008.

DI MAGGIO, Paul. Fronteiras culturais e mudança estrutural: a extensão do modelo de alta cultura ao teatro, à ópera e à dança, 1900-1940. In: LAMNONT, Michèle; FOURNIER, Marcel. (Org.) Cultivando diferenças: fronteiras simbólicas e a formação da desigualdade. São Paulo: Edições SESC, 2015. p. 21-42.

FRAIZ, Priscila. A Dimensão Autobiográfica dos Arquivos Pessoais: o Arquivo de Gustavo Capanema. Estudos Históricos, Rio de Janeiro, v. 11, n. 21, p. 59-88, jul. 1998.

GANS, H. J. Popular Culture \& High Culture: An Analysis amd Evaluation of Taste. New York: Basic Books, 1999.

GARCIA, Maria Madalena Machado. Os Documentos Pessoais no Espaço Público. Estudos Históricos, Rio de Janeiro, v. 11, n. 21, p. 175-187, jul. 1998.

HALBWACHS, Maurice. A Memória coletiva. São Paulo: Centauro, 2006.

HERRERA, A. Heredia. Arquivos, documentos e informação. In: SÃO PAULO (Cidade). Secretaria Municipal de Cultura, Departamento do Patrimônio Histórico. $\mathbf{O}$ direito à memória: patrimônio histórico e cidadania. São Paulo: DPH, 1992. p. 113-120.

HEYMANN, Luciana Quillet. Indivíduo, memória e resíduo histórico: uma reflexão sobre arquivos pessoais e o Caso Filinto Müller. Estudos Históricos, Rio de Janeiro, v. 10, n. 19, p. 41-66, jul. 1997.
HEYMANN, Luciana Quillet. De "arquivo pessoal" a "patrimônio nacional": reflexões acerca da produção de "legados". In: SEMINÁRIO PRONEX DIREITOS E CIDADANIA, 1., Rio de Janeiro, 2-4 ago. 2005, Rio de Janeiro. Anais [...]. Rio de Janeiro: CPDOC, 2005. p. 1-10.

LOPEZ, André Porto Ancona. Arquivos pessoais e as fronteiras da arquivologia. Gragoatá, v. 8, n. 15, p. 69-82, 2003.

MCKEMMISH, Sue. Evidence of me. Archives and Manuscripts, v. 24, n. 1, p. 28-45, 1996.

PORTAL G1. Internautas elegem Encontro das Águas o local 'a cara de Santarém'. 24 jun. 2014. Disponível em: http://g1.globo.com/pa/santaremregiao/noticia/2014/06/internautas-elegemencontro-das-aguas-o-local-cara-de-santarem. html. Acesso em: 10 ago. 2019.

PROCHASSON, Christophe. Atenção: verdade! Arquivos privados e renovação das práticas historiográficas. Revista Estudos Históricos, Rio de Janeiro, v. 11, n. 21, p. 105-120, jul. 1998.

RIBEIRO, Renato Janine. Memórias de si ou... Revista Estudos Históricos, Rio de Janeiro, v. 11, n. 21, p. 35-42, jul. 1998.

ROUSSO, Henry. O arquivo ou o indício de uma falta. Revista Estudos Históricos, Rio de Janeiro, v. 9, n. 17, p. 85-92, jul. 1996.

SANTOS, Paulo Rodrigues dos. Tupaiulândia. Santarém: Tiagão, 1999.

SANTOS FILHO, Osinaldo Lima dos. "Senta e vamos conversar": história de vida de Laurimar Leal e o contexto da "cultura" em Santarém entre 1970 e o início do século XXI. Orientador: Luciana Gonçalves de Carvalho . 2015. 67 f. Monografia (Graduação em Antropologia) - Instituto de Ciências da Sociedade, Universidade Federal do Oeste do Pará, Santarém, 2015.

TANNO, Janete Leiko. Os acervos pessoais: memória e identidade na produção e guarda dos 
registros de si. Patrimônio e memória, v. 3, n. 1, p. 101-111, 2007.

URFALINO, Philippe. L'invention de la politique culturelle. Paris: Hachette Littératures, 2004.
VIDAL, Laurent. Acervos pessoais e memória coletiva - alguns elementos de reflexão. Patrimônio e memória, v. 3, n. 1, p. 3-13, 2007. 